\title{
Functional Outcome of Adulthood Selective Dorsal Rhizotomy for Spastic Diplegia
}

TS Park $^{1}$, So Yeon Uhm ${ }^{2}$, Deanna M. Walter ${ }^{2}$, Nicole L. Meyer ${ }^{2}$, Matthew B. Dobbs ${ }^{3}$

1. Neurological Surgery, Washington University School of Medicine, St. Louis Children's Hospital, St. Louis, USA 2. Pediatric Neurosurgery, Washington University School of Medicine, St. Louis Children's Hospital, St. Louis, USA 3. Pediatric Orthopedic Surgery, Washington University School of Medicine, St. Louis Children's Hospital, St. Louis, USA

Corresponding author: TS Park, tspark@wustl.edu

\section{Abstract}

\section{Objective}

The medical evidence supporting the efficacy of selective dorsal rhizotomy (SDR) on children with spastic diplegia is strong. However, the outcome of SDR on adults with spastic diplegia remains undetermined. The aim is to study the effectiveness and morbidities of SDR performed on adults for the treatment of spastic diplegia.

\section{Methods}

Patients who received SDR in adulthood for the treatment of spastic diplegia were surveyed. The survey questionnaire addressed the living situation, education level, employment, health outcomes, postoperative changes of symptoms, changes in ambulatory function, adverse effects of SDR and orthopedic surgery after SDR.

\section{Results}

The study included 64 adults, who received SDR for spastic diplegia. The age at the time of surgery was between 18 and 50 years. The age at the time of the survey was between 20 and 52 years. The follow-up period ranged from one to 28 years. The study participants reported post-SDR improvements of the quality of walking in $91 \%$, standing in $81 \%$, sitting in $57 \%$, balance while walking $75 \%$, ability to exercise in $88 \%$, endurance in $77 \%$, and recreational sports in $43 \%$. Muscle and joint pain present before surgery improved in $64 \%$ after surgery. Concerning the level of ambulatory function, all patients who walked independently in all environments maintained the same level of ambulatory function. Eighteen percent of the patients who walked independently in some environments improved to the independent walking in all environments. All patients who walked with an assistive device before SDR maintained the assistive walking after SDR. Concerning adverse effects of SDR, 50\% (32 of 64 patients) developed numbness in the various parts of the legs. Two patients reported a complete loss of sensation in parts of the legs, and one patient reported numbness and constant pain in the bilateral lower extremities. Ten patients (16\%) reported recurrent spasticity after SDR, and three patients (5\%) reported ankle clonus, which is an objective sign of

Received 07/01/2019

Review began $07 / 03 / 2019$ Review ended 07/08/2019 Published 07/21/2019

\section{(c) Copyright 2019}

Park et al. This is an open access article distributed under the terms of the Creative Commons Attribution License CC-BY 3.0., which permits unrestricted use, distribution, and reproduction in any medium, provided the original author and source are credited. spasticity. Tendon lengthening surgery after SDR was needed in $27 \%$ and hip and knee surgery in $2 \%$ and $6 \%$, respectively.

\section{Conclusions}

The great majority of our 64 patients, who received adulthood SDR for spastic diplegia, improved the quality of ambulation and abated signs of early aging. Numbness and diminished sensation in the lower extremity was the most common adverse effect of the adulthood SDR.

Categories: Neurosurgery

Keywords: adults, early aging, cerebral palsy, selective dorsal rhiztomy, spasticity

\section{Introduction}

Selective dorsal rhizotomy (SDR) performed in children with spastic diplegia provides the sustained benefits into adulthood [1, 2]. However, cerebral palsy (CP) is not simply a childhood disorder, as many patients live well into adulthood. Adults living with persistent spastic CP suffer from accumulated negative effects of spasticity since early childhood. With advancing age, the adult population develops early aging phenomenon that manifests as muscle weakness, loss of endurance, body pain, and eventual loss of mobility [3, 4]. Whether SDR performed in adulthood can benefit patients with spastic diplegia requires investigation. Previously we reported the outcomes of an initial series of 21 spastic diplegia adult patients who underwent adulthood SDR [5]. The present study included a larger cohort of patients and expanded the scope of the investigation to examine motor functions and the quality of life after adulthood SDR. 


\section{Materials And Methods}

The Institutional Review Board of Washington University School of Medicine approved this retrospective quality of life survey (approval \#201803147). We obtained consent from patients directly or from guardians. The subjects of this study were adults (age > 18 years) with cerebral palsy who received SDR as adults between 1989 and 2018 at St. Louis Children's Hospital. Patients received SDR using the surgical technique previously reported $[6,7]$. Approximately two-thirds of dorsal rootlets at L1-S1 levels were severed through a single level laminectomy. We gathered contact information from emails, mailing addresses, and phone numbers recorded in our clinic's database and medical records. The study survey was sent out to potential participants electronically via email. Letters requesting for updated email addresses were sent out in the mail to potential participants with missing or outdated email addresses.

The survey was constructed with questions on demographic information, living situation, employment status, quality of life, the perception of health, motor and ambulatory functions, braces/orthotics, side effects of SDR, post-SDR treatment, and pain issues. Demographic information included the date of birth, living situation, highest education level, and current work status. Questions about bladder function, numbness, and loss of sensation were asked to assess the side effects of SDR. We asked participants who indicated numbness or loss of sensation in the lower limbs to further indicate if daily activities were hindered due to the loss of sensation. Participants were also inquired about back pain issues, scoliosis, and orthopedic interventions post-SDR.

The Diener Satisfaction with Life Scale (SWLS) was used to assess the quality of life and subjective wellbeing by rating five statements on a scale of one (strongly disagree) to seven (strongly agree). Summary scores on the Diener SWLS are interpreted as follows: 31-35 - extremely satisfied with life, 26-30 - very satisfied, 21-25 - slightly satisfied, 20 - neutral, 15-19 - slightly dissatisfied, 10-14 - very dissatisfied, and 59 - extremely dissatisfied. Reliability of this scale has been reported to be greater than 0.80 [8].

A five-point scale from poor to excellent was utilized to evaluate the perception of one's personal health, as seen in Question 1 of the SF-36 health survey [9]. Yes/no questions were used to measure pre-SDR symptoms: decreased endurance, deterioration of walking, muscle and joint pain, deterioration of balance while walking, decreased the ability to stretch, and feeling of increased spasticity in legs. Yes/no/unchanged questions were used to measure post-SDR symptoms, such as the ones listed above and also the quality of walking, standing, sitting, balance while walking, ability to stretch and exercise, endurance, and ability to participate in recreational sports.

The ambulatory function was assessed by asking patients to indicate their level of function before and after SDR on a three-level classification system. Level I includes patients who can walk on their own without using walking aids, go up and down the stairs without needing to hold the handrail, walk wherever they want to go, and run and jump although their speed, balance, and coordination may be slightly limited. Patients at level II can walk on their own without using walking aids, but need to hold onto the handrail when going up and down the stairs and often find it difficult to walk on uneven surfaces, slopes, or in crowds. Lastly, level III includes patients who can stand on their own, only walk using a walking aid, find it difficult to climb stairs or walk on uneven surfaces, and may use a wheelchair when traveling for long distances or in crowds.

Experiences with pain were gauged by asking participants to report back pain and the severity of pain on the Numeric Pain Rating Scale (NPRS). The NPRS is a 0-10 scale with 0 indicating no pain and 10 being the worst pain imaginable. We asked for the location of the pain and any interventions they received to alleviate pain, such as care from a physician, medications, surgical treatment, physical therapy, and injection treatment for back pain.

\section{Results \\ Study Cohort}

The number of patients who received selective dorsal rhizotomy during adulthood totals to be 139 patients. Their most up-to-date contact information was gathered from the Center for Cerebral Palsy Spasticity at St. Louis Children's Hospital's databases. Due to outdated contact information, 21 patients could not be reached. Out of the remaining 118 potential participants, three patients declined the study, and 81 responses were collected. From the collected responses, 17 responses were omitted because either the postSDR follow-up period was less than one year or the patients were not diagnosed with spastic diplegia. Ultimately, the total number of patient responses used in the study totals to be 64 , which represents $54 \%$ of potential participants who met the study criteria.

\section{Demographics of Study Cohort}

Of the 64 patients who received SDR for spastic diplegia, the age at the time of surgery was between 18.1 and 50.0 years (mean age: $31.6 \pm 9.1$ years). The postoperative follow-up period ranges from 1.0 and 28.2 years (mean duration: $6.6 \pm 5.5$ years). Age at follow-up varied from 20.2 to 52.3 years (mean age: $38.1 \pm 9.0$ years). Male participants made up $58 \%$ of the study population (Table 1 ). 


\section{Cureus}

\begin{tabular}{|l|l|}
\hline Study population & Value \\
\hline Total number of patients & 64 patients \\
\hline Age at surgery & $18.1-50.0$ years (mean $31.6 \pm 9.1)$ \\
\hline Age at follow-up survey & $20.2-52.3$ years (mean $38.1 \pm 9.0)$ \\
\hline Follow-up period & $1.0-28.2$ years (mean $6.6 \pm 5.5)$ \\
\hline Sex & $\%$ of total patients \\
\hline Male & $37(58 \%)$ \\
\hline Female & $27(42 \%)$ \\
\hline
\end{tabular}

\section{TABLE 1: Demographics of 64 adult diplegic patients at the time of surgery}

mean \pm standard deviation

\section{Living Situation, Education, and Employment}

Fifty-three percent of participants live with a significant other, $23 \%$ live alone, $17 \%$ live with parents, and $6 \%$ has other living situations. Question about the highest level of education reveals that $2 \%$ received less than a high school diploma, $17 \%$ received a high school diploma, $2 \%$ went to vocational school, $9 \%$ received an associate degree, $45 \%$ got a bachelor's degree, $22 \%$ got a master's degree, and $3 \%$ received a doctorate. At the time of the survey, $72 \%$ of all patients were employed, with $63 \%$ working full-time, $22 \%$ part-time, and 15\% unspecified (Table 2). 


\section{Cureus}

\begin{tabular}{|l|l|}
\hline Living Situation & \% of total patients \\
\hline With Significant Other & 53 \\
\hline Alone & 23 \\
\hline With Parents & 17 \\
\hline Other & 6 \\
\hline Education & $\%$ of total patients \\
\hline Less than high school & 2 \\
\hline High school diploma & 17 \\
\hline Vocational school & 2 \\
\hline Associate degree & 9 \\
\hline Bachelor's degree & 45 \\
\hline Master's degree & 22 \\
\hline Doctorate & 3 \\
\hline Employment & $\%$ of total patients \\
\hline Employed & 72 \\
\hline Type of employment & $\%$ of employed patients \\
\hline Full-time & 63 \\
\hline Part-time & 22 \\
\hline Unspecified & 15 \\
\hline
\end{tabular}

TABLE 2: Living situation, education, and employment at the time of the survey in 64 adult diplegic patients

\section{Life and Health Perception}

Majority of the participants responded that they perceived their health as good or better (92\%), $6 \%$ as fair, and $2 \%$ as poor. Most participants were classified in the slightly satisfied bracket of the Diener SWLS, with the mean overall score being $24.1 \pm 7.4$ (Table 3).

\begin{tabular}{|l|l|}
\hline Satisfaction with Life Scale (SWLS) & Value \\
\hline SWLS score & $5-35$ (mean $24.1 \pm 7.4)$ \\
\hline Perception of health & $\%$ of total patients \\
\hline Excellent & 20 \\
Very good & 38 \\
Good & 34 \\
Fair & 6 \\
\hline Poor & 2 \\
\hline
\end{tabular}

TABLE 3: Satisfaction with Life and Health Perception at the time of follow-up in 64 adult patients mean \pm standard deviation 


\section{Cureus}

\section{Preoperative Symptoms and Postoperative Improvement}

Before SDR, $83 \%$ of all patients experienced decreased endurance, $88 \%$ deterioration of walking, $81 \%$ muscle and joint pain, $87 \%$ deterioration of balance while walking, $92 \%$ decreased ability to stretch, and $91 \%$ feeling of increased spasticity in legs. SDR alleviated decreased endurance in $77 \%$ of the group, deterioration of walking in $86 \%$, muscle and joint pain in $64 \%$, deterioration of balance while walking in $78 \%$, decreased the ability to stretch in $88 \%$, and feeling of increased spasticity in legs in $85 \%$. (Table 4 ).

\begin{tabular}{|c|c|c|c|}
\hline & $\begin{array}{l}\text { Did you have the following symptoms before } \\
\text { SDR? }\end{array}$ & \multicolumn{2}{|c|}{$\begin{array}{l}\text { Do you think SDR improved the following } \\
\text { symptoms? }\end{array}$} \\
\hline & Pre-SDR & \multicolumn{2}{|l|}{ Post-SDR } \\
\hline & (\% of total patients) & Yes (\% of total patients) & No ( $\%$ of total patients) \\
\hline Decreased endurance & 83 & 77 & 23 \\
\hline Deterioration of walking & 88 & 86 & 14 \\
\hline Muscle and joint pain & 81 & 64 & 36 \\
\hline $\begin{array}{l}\text { Deterioration of balance while } \\
\text { walking }\end{array}$ & 87 & 78 & 22 \\
\hline Decreased ability to stretch & 92 & 88 & 12 \\
\hline $\begin{array}{l}\text { Feeling of increased spasticity in } \\
\text { legs }\end{array}$ & 91 & 85 & 15 \\
\hline
\end{tabular}

TABLE 4: Symptoms and signs before and after selective dorsal rhizotomy in 64 adult diplegic patients

\section{Postoperative Improvements in Motor Functions}

Other symptoms were improved as well, including improved quality of walking in 91\%, better standing and sitting in $81 \%$ and $57 \%$ respectively, better balance while walking in $75 \%$, increased ability to exercise and stretch in $88 \%$ and $89 \%$ respectively, improved endurance in $77 \%$, and enhanced ability to partake in recreational sports in $43 \%$ (Table 5).

Do you think SDR improved the following?

Quality of walking

Standing

Sitting

Balance while walking

Ability to exercise

Ability to stretch

Endurance

Recreational sports
$\%$ of total patients

$\begin{array}{ll}\text { Yes } & \text { No } \\ 91 & 9 \\ 81 & 19 \\ 57 & 43 \\ 75 & 25 \\ 88 & 12 \\ 89 & 11 \\ 77 & 23 \\ 43 & 57\end{array}$

TABLE 5: Functional outcome after selective dorsal rhizotomy in 64 adult diplegic patients

\section{Postoperative Changes in Ambulatory Function}

Before receiving SDR, 30\% walked independently in all environments, 57\% in some environments, and 13\% required an assistive device to ambulate. After the SDR, the percentage of participants who ambulates 
independently in all environments increased by $18 \%$. Thirty-nine percent can ambulate independently in some environments, and $13 \%$ require the assistive device. Overall, $23 \%$ of the group improved ambulatory function, $70 \%$ showed an unchanged level of function, and more than $7 \%$ experienced worsened function. Twenty-five percent indicated the use of lower limb orthotics at the time of the survey (Table 6).

\begin{tabular}{|l|l|}
\hline Ambulatory Function Before and After SDR & $\%$ of total patients \\
\hline & Before SDR \\
\hline Independent ambulation in all environments & 30 \\
\hline Independent ambulation in some environments & 57 \\
\hline Ambulation with an assistive device & 13 \\
\hline
\end{tabular}

TABLE 6: Changes in the ambulatory function of 64 diplegic patients after selective dorsal rhizotomy

Postoperative Spasticity, Bladder Function, Sensory Changes, and Pain

Sixteen percent of the patients reported recurrent spasticity after SDR. Ankle clonus was reported in 5\%, and urinary incontinence was observed in 13\% (eight patients) of the group, which decreased to $3 \%$ (two patients) after SDR. Out of the eight patients who experienced urinary incontinence before SDR, seven patients did not report incontinence post-SDR. One patient had continuing urinary incontinence, while one patient developed incontinence after SDR. Upon review of clinic notes for the patient who developed urinary incontinence after SDR, it was found that no significant urinary control problems were indicated after SDR. Some patients with cerebral palsy can suffer from neurogenic bladder and incontinence even without SDR [10]. The incontinence occurred long after SDR in the patient. Therefore, the patient's experience with urinary incontinence cannot be determined as a result of SDR with certainty. Urinary incontinence medications were taken in $2 \%$ of the population both before and after SDR.

Numbness in lower extremities was reported in $50 \%$, out of which $22 \%$ of the patients experienced numbness affecting daily activities. The most common locations that patients experienced numbness at were the outer parts of the calves and feet. Complete loss of sensation in small areas of the legs was noted in $5 \%$ of all patients, which was most frequently experienced below the knee and the posterior parts of the thigh.

Back pain was reported in $56 \%$ ( 36 patients) of the patient cohort. Out of the 36 patient experiencing back pain, 13 patients had continuing back pain from pre-SDR. Seven patients had back pain prior to SDR, which disappeared after the surgery. Six patients reported back pain during the post-SDR follow-up visit. Ten patients had no reported back pain before and after SDR, but developed back pain over a longer period of time after SDR. Because back pain was not reported at the post-SDR follow-up visit, it cannot be determined with certainty whether the pain in the back is a result of SDR. On the Numeric Pain Rating Scale of 0 - 10 with 0 representing no pain and 10 being worst pain imaginable, mean back pain score was $4.4 \pm 2.2$. Location of pain was most frequently identified to be the lower back (77\% of patients with pain) and middle back (16\%). Most patients received physical therapy for back pain (58\%) and medications (33\%). More invasive treatments for back pain, such as surgical treatment or injections, were not pursued by many patients, with percentages remaining at $6 \%$ and $17 \%$ respectively (Table 7 ). 


\section{Cureus}

\begin{tabular}{|c|c|c|}
\hline Recurrent spasticity & \multicolumn{2}{|c|}{ Number of patients (\% of total patients) } \\
\hline Recurrent spasticity after SDR & \multicolumn{2}{|l|}{$10(16 \%)$} \\
\hline Ankle clonus after SDR & \multicolumn{2}{|l|}{$3(5 \%)$} \\
\hline \multirow[t]{2}{*}{ Bladder function } & \multicolumn{2}{|c|}{ Number of patients (\% of total patients) } \\
\hline & Before SDR & After SDR \\
\hline Urinary Incontinence & $8(13 \%)$ & $2(3 \%)$ \\
\hline Medications for urinary incontinence & $1(2 \%)$ & $1(2 \%)$ \\
\hline Sensory changes & \multicolumn{2}{|c|}{ Number of patients (\% of total patients) ${ }^{*}$} \\
\hline Numbness after SDR & \multicolumn{2}{|l|}{$32(50 \%)$} \\
\hline \multirow[t]{2}{*}{ Complete loss of sensation in parts of legs } & \multicolumn{2}{|l|}{$3(5 \%)$} \\
\hline & \multicolumn{2}{|c|}{$\%$ of patients with numbness } \\
\hline Numbness affects daily activities & \multicolumn{2}{|l|}{$7(22 \%)$} \\
\hline Back pain & \multicolumn{2}{|c|}{ Number of patients (\% of total patients) } \\
\hline Back pain & \multicolumn{2}{|l|}{$36(56 \%)$} \\
\hline Back Pain Score & \multicolumn{2}{|c|}{ Numerical Rating Scale $(0-10)$} \\
\hline Average pain score & \multicolumn{2}{|c|}{$1.5-9.2($ mean $4.4 \pm 2.2)$} \\
\hline Location of back pain of patients experiencing back pain & \multicolumn{2}{|c|}{ Number of patients (\% of patients with back pain) ${ }^{\star \star}$} \\
\hline Low & \multicolumn{2}{|l|}{$33(77 \%)$} \\
\hline Middle & \multicolumn{2}{|l|}{$7(16 \%)$} \\
\hline Upper & \multicolumn{2}{|l|}{$3(7 \%)$} \\
\hline Received treatment from physicians for back pain & \multicolumn{2}{|l|}{$10(28 \%)$} \\
\hline Medications for back pain & \multicolumn{2}{|l|}{$12(33 \%)$} \\
\hline Surgical treatment for back pain & \multicolumn{2}{|l|}{$2(6 \%)$} \\
\hline Physical therapy for back pain & \multicolumn{2}{|l|}{$21(58 \%)$} \\
\hline Injection treatment for back pain & \multicolumn{2}{|l|}{$6(17 \%)$} \\
\hline
\end{tabular}

TABLE 7: Bladder function, sensory changes, and pain after selective dorsal rhizotomy in 64 adult diplegic patients

SDR - selective dorsal rhizotomy

mean \pm standard deviation

*Numbness and complete loss of sensation was most commonly experienced in the calves

**ain can be experienced in multiple locations by one patient

\section{Post-SDR Orthopedic Surgery}

Post-SDR hip surgery and knee surgery were undergone in $2 \%$ and $6 \%$ of patients, respectively. Tendon lengthening surgery after SDR was reported in $27 \%$ of the population. The most common orthopedic surgeries among the patients who received orthopedic interventions were hamstring lengthening (47\%), Achilles tendon lengthening (37\%), adductor lengthening (5\%), and calf muscles lengthening (11\%) (Table 8). 


\section{Cureus}

\begin{tabular}{|l|l|}
\hline Post-SDR orthopedic surgery & Number of patients $(\%$ of total patients) \\
\hline Hip surgery & $1(2 \%)$ \\
\hline Knee surgery & $4(6 \%)$ \\
\hline Tendon lengthening surgery & $17(27 \%)$ \\
\hline Type of tendon lengthening surgery & $\%$ of tendon lengthening patients \\
\hline Hamstrings & $9(47 \%)$ \\
\hline Achilles tendon & $7(37 \%)$ \\
\hline Adductors & $1(5 \%)$ \\
\hline Calf muscles & $2(11 \%)$ \\
\hline
\end{tabular}

\section{TABLE 8: Post-SDR orthopedic surgery in 64 adult diplegic patients}

SDR - selective dorsal rhizotomy

"Each patient may have received more than one kind of surgery

\section{Discussion}

The present study shows strong evidence that the reduction of spasticity with SDR in adults with spastic diplegia likely reverses or halts deteriorating ambulation. Until now, when the adults were losing the ability to walk due to persistent spasticity, no treatment was deemed available that can prevent the late onset of functional loss. Our clinical experience of treating adults with SDR up to 50 years of age allowed us to learn more about the negative effects of persistent CP spasticity in adults. As they age, the adults develop increasingly tight muscles, tendons, and joints; sitting, standing and walking become increasingly limited; endurance can decrease in a short time frame; muscle and joint pain increases; they often lose the ability to walk before 50 years of age. The late functional decline in adults with spastic cerebral palsy has been recognized in the clinical arena [3, 4]. The natural course of spastic diplegia in adults should be weighed against the postoperative adverse effects of SDR.

The main goal of SDR on adults is a reversal or cessation of the declining ambulatory and other motor functions. In our patients, the great majority improved the ambulatory function after SDR. The quality of independent walking improved in $91 \%$ of study participants. Those who were independent ambulators before surgery maintained the independent ambulation after surgery. Also, the ability to exercise improved in $88 \%$ of participants. In contrast, sitting ability did not improve in $43 \%$. We assume the floor sitting failed to improve in the group.

Another goal of SDR on adults is relief of muscle and joint pain. Eighty-one percent of participants had body pain before surgery. It is significant that $36 \%$ of them persisted with body pain with no improvement. Some study participants describe electric shock pain, pins and needle pain, nerve pain, radiating pain, and spasms that were not present before SDR. One female participant who underwent SDR at 48 years of age developed constant severe pain in the entire lower extremities. The pain is not relieved by medication, and the cause of the pain is unclear. Future patients should be informed of the possible new pain after SDR. Also, the pain outcome should be a factor in the selection of adults for SDR. Patients who have generalized or localized pain that is resistant to pain medication may not benefit from SDR. The persistent pain would have a dominating impact on the overall quality of life, even after spasticity is reduced.

Adulthood SDR had more negative outcomes than childhood SDR [1, 2]. The most common problem after SDR in adults was numbness in the legs. Fifty percent of participants had varying severity and extent of numbness. The numbness affected daily life in $22 \%$ of participants. While the numbness was most often present in parts of the legs, participants who had surgery near 50 years of age developed numbness below one or both knees. One participant persists with constant severe numbness in the entire lower extremities. In one participant, the numbness does not allow her to be comfortable in jeans anymore. It is of note that after childhood SDR, the numbness occurred infrequently and did not affect daily activities. The cause of frequent and severe numbness following adulthood SDR is unclear.

Ten survey participants (16\%) felt persistent spasticity or a return of spasticity. Three participants (5\%) reported ankle clonus. One participant described a gradual return of spasticity approximately one year after surgery. She had no clonus. She underwent the baclofen pump placement and bilateral knee replacements. Reasons for other participants to feel persistent or a return of spasticity include spasticity in the quadriceps 
because of a catch during a fast stretch, muscle imbalance between quadriceps and hamstrings, only returned in the left Achilles tendon, and spasms in the legs. Whether spasticity can return to only one muscle is unclear. It should be noted that the reported spasticity in the ten adults was not verified by neurological examination. In some of the patients, the tight muscles may have been mistaken for spasticity.

\section{Conclusions}

In conclusion, the present study shows that SDR on adults can benefit patients with spastic diplegia up to 50 years of age. However, adulthood SDR may be associated with adverse outcomes, i.e., numbness, and failure to reduce spasticity and body pain. The adverse outcomes were more common in patients over 40 years of age.

\section{Additional Information \\ Disclosures}

Human subjects: Consent was obtained by all participants in this study. The Institutional Review Board of Washington University School of Medicine issued approval 201803147. Animal subjects: All authors have confirmed that this study did not involve animal subjects or tissue. Conflicts of interest: In compliance with the ICMJE uniform disclosure form, all authors declare the following: Payment/services info: All authors have declared that no financial support was received from any organization for the submitted work. Financial relationships: All authors have declared that they have no financial relationships at present or within the previous three years with any organizations that might have an interest in the submitted work. Other relationships: All authors have declared that there are no other relationships or activities that could appear to have influenced the submitted work.

\section{References}

1. Park TS, Edwards C, Liu JL, Walter DM, Dobbs MB: Beneficial effects of childhood selective dorsal rhizotomy in adulthood. Cureus. 2017, 9:e1077. 10.7759/cureus.1077

2. Park TS, Liu JL, Edwards C, Walter DM, Dobbs MB: Functional outcomes of childhood selective dorsal Rrhizotomy 20 to 28 years later. 2017, 28:e1256. 10.7759/cureus.1256

3. Balandin S, Morgan J: Adults with cerebral palsy: what's happening?. J Intellectual Develop Disability. 1997, 22:109-124. 10.1080/13668259700033341

4. Tosi LL, Maher N, Moore DW, Goldstein M, Aisen ML: Adults with cerebral palsy: a workshop to define the challenges of treating and preventing secondary musculoskeletal and neuromuscular complications in this rapidly growing population. Dev Med Child Neurol. 2009, 51:2-11. 10.1111/j.1469-8749.2009.03462.x

5. Reynolds MR, Ray WZ, Strom RG, Blackburn SL, Lee A, Park TS: Clinical outcomes after selective dorsal rhizotomy in an adult population. World Neurosurg. 2011, 75:138-144. 10.1016/j.wneu.2010.09.010

6. Park TS, Gaffney PE, Kaufman BA, Molleston MC: Selective lumbosacral dorsal rhizotomy immediately caudal to conus medullaris for cerebral palsy spasticity. Neurosurgery. 1993, 33:929-934. 10.1097/00006123199311000-00026

7. Park TS, Johnston JM: Selective dorsal rhizotomy for spastic cerebral palsy. Pediatric Neurosurgery: Neurosurgical Operative Atlas. Goodrich JT (ed): Thieme, Stuttgard; 2008. 177-183. 10.1055/b-0034-72758

8. Diener E, Emmons RA, Larsen RJ, Griffin S: The Satisfaction With Life Scale. J Pers Assess. 1985, 49:71-75. 10.1207/s15327752jpa4901_13

9. Brazier JE, Harper R, Jones NM, et al.: Validating the SF-36 health survey questionnaire: new outcome measure for primary care. BMJ. 1992, 305:160-164. 10.1136/bmj.305.6846.160

10. Goldfarb RA, Pisansky A, Fleck J, et al.: Neurogenic lower urinary tract dysfunction in adults with cerebral palsy: outcomes following a conservative management approach. J Urol. 2016, 195:1009-1013. 10.1016/j.juro.2015.10.085 